\title{
ESTIMATING ACCURACY OF MEASURING LENGTH OF ROUND TIMBER PRODUCED IN LOGGING BY WORKING WITH HARVESTER
}

\author{
Aigars Strubergs ${ }^{1}$, Aleksandrs Saveljevs ${ }^{1}$, Maris Davidans ${ }^{1}$, Sergey Ariko ${ }^{2}$ \\ ${ }^{1}$ Latvia University of Life Sciences and Technologies, Latvia; \\ ${ }^{2}$ Belarusian State Technological University, Belarus \\ aigars.strubergs@hotmail.com, silvasav@1lu.lv,maris.davidans@1lu.lv, sergeyariko@mail.ru
}

\begin{abstract}
Analyzing in forestry prepared round timber, it has been found that the accuracy of the measurement of length is due both to the unbundling of assortment in timber processing plants and the irrational absorption of prepared tree trunks. Researches have been conducted in the need for calibration of the harvester working mechanism, but there is no research on the effect of the length measuring roller on the length of the assortment precision. The aim of the work is to determine the impact of the assortment length measuring roller on the measurement accuracy. These researches are made in the year of 2016 in different seasons, using a harvester working mechanism with interchangeable three-roller shapes.In the research 1696 assortments were gauged. During the processing of the data obtained, a precision roller was determined for measuring the length, which ensures the minimum length inaccuracy throughout the year. It has been found that the tree species, annual seasonality and the planned length of assortments influence the accuracy of measuring the length regardless of the shape of the roller. In each situation it is advisable to use the most appropriate form of the measuring roller.
\end{abstract}

Key words: harvester, assortment length measurement, precision.

\section{Introduction}

It is relatively difficult to precisely determine the volume of assorted assemblies during harvesting, given that the tree is not a valid geometric figure, therefore, several measurements and complicated calculations are required [1]. Measuring of cut timber assortments is carried out in two ways: individual and group [2]. The volume of wood assortment is influenced by two components: the diameter of the assortment and the length of the assortment. In the world, many loggers pay more attention to the precise assortment of diameters, rather than the length of assortment. An inadequate work-assortment can be a reason for breaking the assortment, while the diameter effect can only be in place of diameters of group changes [3]. In Latvia, the assortment lengths must not be less than those prescribed in the work order with a tolerance of up to $+6 \mathrm{~cm}$ from the length of the assortment [4]. For harvesting harvesters, assortment length measurement mechanisms are most often set up on the encoder principle [5; 6], which is based on the registration of an electrical signal and depicted on a computer screen in a readable form (digital). In the process of generating electrical signals to the encoder, a length measuring roller inserted in the harvester's working head mechanically rotates on the measured surface in the branched trunk of the trunk. Several authors $[7 ; 8 ; 9]$ note that the shape of the length measuring rollers and the configuration of the tooth can vary, and need to be changed, if necessary, taking into account the fact that cutting the cut wood using a harvester occurs dynamically as well as in changing natural conditions. Due to the individual characteristics of the cut wood, measurement causes measurement errors that affect the results of the produced round wood $[9 ; 10]$.

Based on the above, the aim of the work is to find out the most appropriate configuration of the measuring roller and the conditions affecting the accuracy of the assortment length measurements, as well as the influence of different conditions (tree species, season, length of assortment) on the length of the prepared round timber.

\section{Materials and Methods}

Observations were made in the central region of Latvia in the Vidusdaugava region, in the type of forest growing conditions - the lan, cleared in a forest stand, where coniferous trees (pine and spruce) dominate with the average volume of trees under consideration $V_{k}=0.54 \mathrm{~m}^{3}$.

Observations were made in two years: the average air temperature above $0{ }^{\circ} \mathrm{C}$ and the average temperature below $0{ }^{\circ} \mathrm{C}$ focused on the external state of the tree trunks: the dry trunk and the wet (iced) trunk.

The logging was done with a John Deere 1070D harvester (having regard to the length of the assortments specified in LVS 82: 2003 [11]), with the ability to change the length measuring roller shape in three variations: 

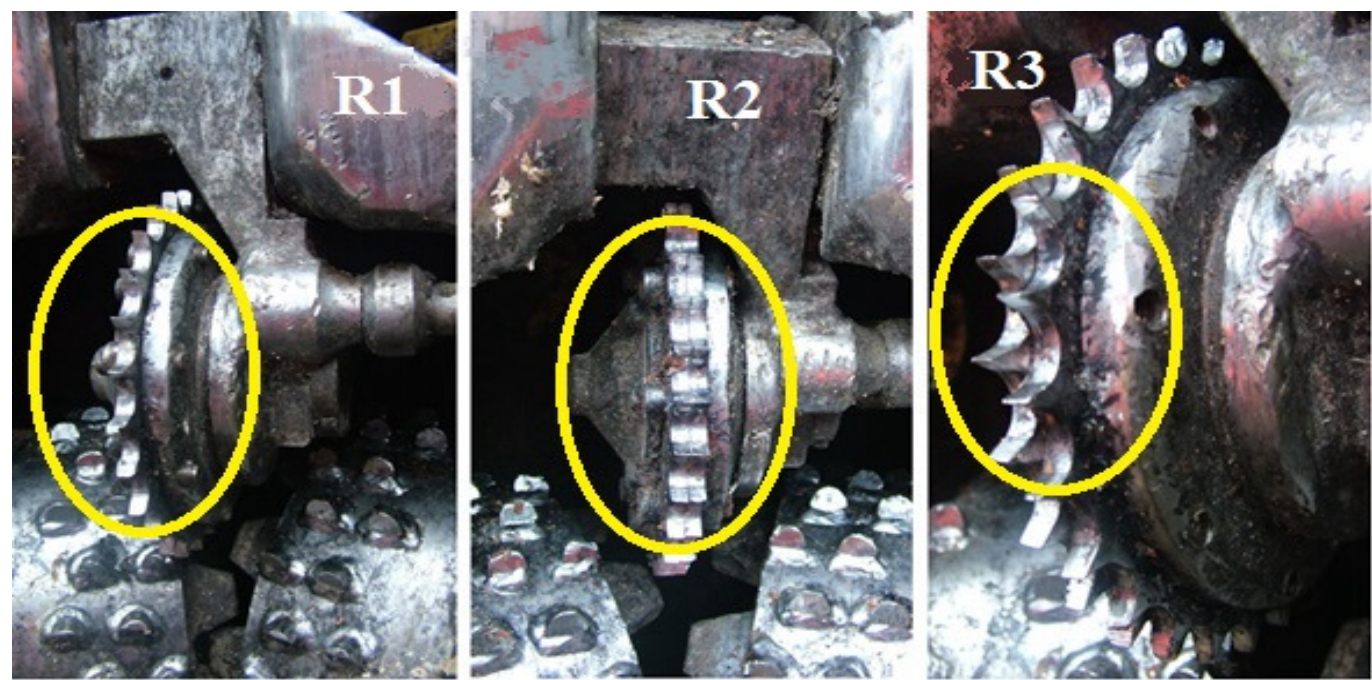

Fig. 1. Length measuring rollers

- standard roller R1;

- double mounted standard roller wheels with adjoining teeth, R2;

- double standard rollers with intermediate gears, R3.

In this reaseach 1696 round timber assortments were gauged in different sections of the trunk. The measurement was made using a verified tape measure with an accuracy of $\pm 1 \mathrm{~cm}$ and the assortment lengths obtained were compared with the output of an automatically-assembled assortment of the harvester board computer printout.

Using the features in Microsoft Office Excel 2013, the formula was used:

$$
\Delta L=l_{\text {fact }}-l_{\text {norm }},
$$

where $\Delta L$-assortment length deviation;

$l_{\text {fact }}$ - assortment length measured with tape measure, $\mathrm{cm}$;

$l_{\text {norm }}$ - planned length of the assortment with the permissible surface, $\mathrm{cm}$.

Deviation of length of assortment with each length measuring roller (R1; R2; R3) was determined for both different seasons of the year for different assortment types.

Deviations of the obtained length are divided into four groups:

- negative size group - the assortment length is shorter than the nominal;

- "0" - in this size group - assortment lengths of exactly 0 to $+3 \mathrm{~cm}$ coincide with the nominal;

- increased but permissible deviation - the assortment length is increased, but the tolerance is +3 to $+6 \mathrm{~cm}$;

- increased deviation - the assortment length is increased above $+6 \mathrm{~cm}$.

\section{Results and discussion}

In total 1696 round timbers were evaluated, 676 assortments were prepared and tested with roller $\mathrm{R} 1,765$ assortment with roller R2 and assortment 257 with roller R3.

The results of the research show that at low air temperatures, when tree trunks tend to be icing, the standard length measuring mechanism roller (R1) gives the best result, only $35 \%$ of the assortments have a deviation from the nominal length, and from them shorter than the nominal length $-13 \%$ of assorted assortments.

R2 and R3 configuration length measuring rolls make up $44 \%$ to $52 \%$, respectively, of the cutoff assortment, an inaccuracy in measuring length over the permissible $0+3 \mathrm{~cm}$ in $32-40 \%$ assemblies is shorter than the nominal (Fig. 2. a).

In a period, when the air temperature is above $0{ }^{\circ} \mathrm{C}$, the situation is the opposite. The standard length measuring mechanism with roller R1 gives an incorrect measurement of length in $23 \%$ cases, where in $12.6 \%$ of the cut length the assortment is shorter than the nominal size. When using rollers 
R2 and R3, a similar situation was observed as inappropriately cut assortments in total amount to 10$11 \%$ in the shortest total assortment of 3.0-4.3\% (Fig. 1. b).

a)

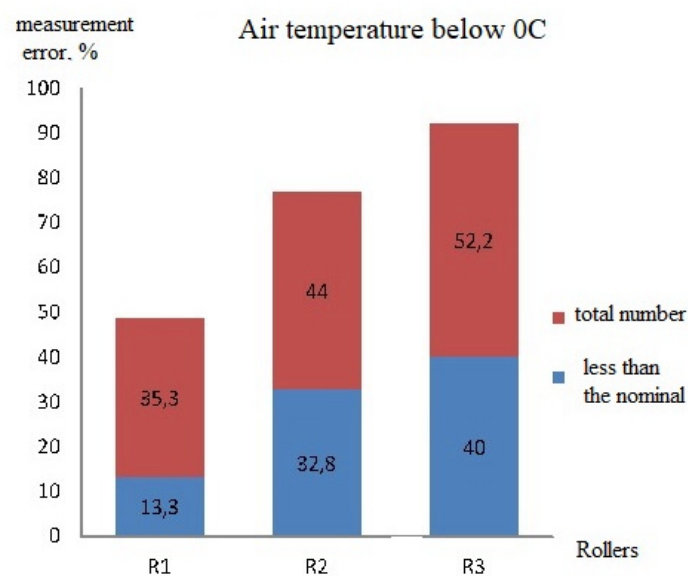

b) measurement error. $\%$

Air temperature above $0 \mathrm{C}$

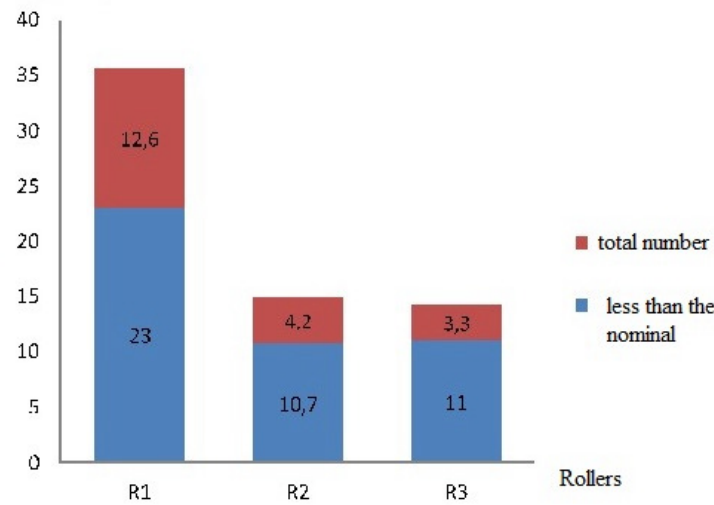

Fig. 2. Proportion of assortment with inappropriate length to nominal: $\mathrm{a}$ - air temperature below $0{ }^{\circ} \mathrm{C} ; \mathrm{b}$ - air temperature above $0{ }^{\circ} \mathrm{C}$

In a detailed analysis it was concluded that for preparation of large dimensions (4.9-6.1 m) at low temperatures $\left(t^{\mathrm{o}} \leq 0\right)$ there are more common denominator errors. Table 1 shows that largerdimensional assortments have more frequent variations in length. The varieties are either taller or shorter than the nominal length.

Table 1

Accuracy of the assortment length of the pins (min-max) to the nominal size according to the total assortment of assorted assortments $\left(t \leq 0{ }^{\circ} \mathrm{C}\right)$

\begin{tabular}{|c|c|c|c|c|c|c|}
\hline \multirow{2}{*}{ Rollers } & \multicolumn{2}{|c|}{$\begin{array}{c}\text { fat assortments } \\
d>28 \mathrm{~cm} \\
l=3.1 ; 4.9 ; 6.1 \mathrm{~m}\end{array}$} & \multicolumn{2}{|c|}{$\begin{array}{c}\text { medium assortments } \\
d=18-28 \mathrm{~cm} \\
l=4.9 ; 6.1 \mathrm{~m}\end{array}$} & \multicolumn{2}{|c|}{$\begin{array}{c}\text { small assortments } \\
d<18 \\
l=3.0 ; 3.7 \mathrm{~m} \\
\end{array}$} \\
\hline & $\begin{array}{l}\text { longer than } \\
\text { the nominal }\end{array}$ & $\begin{array}{c}\text { less than the } \\
\text { nominal }\end{array}$ & $\begin{array}{c}\text { longer than } \\
\text { the } \\
\text { nominal }\end{array}$ & $\begin{array}{l}\text { less than } \\
\text { the } \\
\text { nominal }\end{array}$ & $\begin{array}{l}\text { longer than } \\
\text { the nominal }\end{array}$ & $\begin{array}{c}\text { less than the } \\
\text { nominal }\end{array}$ \\
\hline $\mathrm{R} 1$ & $14.6-42.1 \%$ & $5.3-12.5 \%$ & $12.8 \%$ & $12.8 \%$ & $7.0-21.0 \%$ & $5.3-32.0 \%$ \\
\hline $\mathrm{R} 2$ & $19.6-50.0 \%$ & $13.0-26.5 \%$ & $26.7 \%$ & $46.7 \%$ & $0-14.3 \%$ & $11.0-23.0 \%$ \\
\hline R3 & $62.0 \%$ & 0 & $40.0 \%$ & 0 & $0-22.0 \%$ & $0-13.6 \%$ \\
\hline
\end{tabular}

In the warm period of the year $\left(t^{\circ}>0\right)$ the situation is reflected in Table 2, where it is seen that in all dimensions of the assortments the deviation from the nominal length is similar.

In general, it was found that the lengths of the assortments measured in the warm seasons $\left(t>0{ }^{\circ} \mathrm{C}\right)$ are $17.7 \%$ more accurate than in the cold season, when $\left(t \leq 0^{\circ} \mathrm{C}\right)$.

The analysis of the obtained data dispersion shows that in the cold season $\left(t \leq 0{ }^{\circ} \mathrm{C}\right)$, the standard roller assortments, on average, $15.6 \%$ of the total could be broken down due to the smallest relative to the nominal length ratio and, on average, $15 \%$, the assortment lengths were made longer than the allowable margin nominal assortment length.

The roller R2, where the two standard gears were painted (actually double the width of the gear), showed good results during the warm season $\left(t>0{ }^{\circ} \mathrm{C}\right)$, but in comparison with the standard roller during the cold season $\left(t \leq 0{ }^{\circ} \mathrm{C}\right)$, such a roller more often slips or slides faster to the stem roughness, as a result, the proportion of shorter assortments in the cold season is significant - an average of $23 \%$.

The roller R3, where the two standard gears are painted so that the needle is interchangeable (actually the sprocket is wider and the wound is more frequent), showed very poor results in the cold season $\left(t \leq 0{ }^{\circ} \mathrm{C}\right)$, when on average $35 \%$ of all assortments are significantly longer than nominal assortment length and permissible tolerance. However, assortment assemblies prepared in the warm seasons are the most accurate for the nominal length of the size. 
Table 2

Accuracy of the assortment length of the pins (min-max) to the nominal size according to the total assortment of assorted assortments $\left(t>0{ }^{\circ} \mathrm{C}\right)$

\begin{tabular}{|c|c|c|c|c|c|c|}
\hline \multirow{2}{*}{ Rollers } & \multicolumn{2}{|c|}{$\begin{array}{c}\text { fat assortments } \\
d>28 \mathrm{~cm} \\
l=3.1 ; 4.9 ; 6.1 \mathrm{~m}\end{array}$} & \multicolumn{2}{|c|}{$\begin{array}{c}\text { medium assortments } \\
d=18-28 \mathrm{~cm} \\
l=4.9 ; 6.1 \mathrm{~m}\end{array}$} & \multicolumn{2}{|c|}{$\begin{array}{c}\text { small assortments } \\
d<18 \\
l=3.0 ; 3.7 \mathrm{~m} \\
\end{array}$} \\
\hline & $\begin{array}{l}\text { longer than } \\
\text { the nominal }\end{array}$ & $\begin{array}{c}\text { less than the } \\
\text { nominal }\end{array}$ & $\begin{array}{l}\text { longer than } \\
\text { the } \\
\text { nominal }\end{array}$ & $\begin{array}{l}\text { less than } \\
\text { the } \\
\text { nominal }\end{array}$ & $\begin{array}{l}\text { longer than } \\
\text { the nominal }\end{array}$ & $\begin{array}{c}\text { less than the } \\
\text { nominal }\end{array}$ \\
\hline $\mathrm{R} 1$ & $13-17.6 \%$ & $4.3-14.7 \%$ & $3.3-3.8 \%$ & $1.5-15.4 \%$ & $0-14.3 \%$ & $11.4-23.8 \%$ \\
\hline R2 & $5-14.9 \%$ & $0-6.4 \%$ & $2.3-15 \%$ & $4.7-15 \%$ & $0-6 \%$ & $4.5-15.4 \%$ \\
\hline R3 & $10-23.5 \%$ & $0-13.6 \%$ & $0-7.1 \%$ & $0-4.2 \%$ & $0-22.2 \%$ & $0-13.6 \%$ \\
\hline
\end{tabular}

The hypothesis has also been confirmed - the assortment thickness indices (diameter and nominal length) influence the accuracy of the length measuring mechanism. Namely, the largest and potentially heavier assortments at the moment of pruning, with their inertia, increase the physical dimension of the length more frequently against the nominal harvester harvesting program.

It was also concluded that by increasing the size of the roller mass by attaching extra load to the standard bracket, the inertia of the movement increases, and in the assorted assemblies there is a greater dispersion in the length measurement, that is, the physical incompatibility increases for the actual length of the assortment of nominal size.

A similar situation has been observed in the production of spruce (Picea pungens L.) assortments and the results practically coincide with the results obtained in the production of pine assortments.

\section{Conclusions}

1. In the cold season, with a length measuring roller for the R1 prepared assortments, a deviation from the nominal length of 5.3 to $42 \%$ of the number of assortments prepared was observed. With length measurement rollers R2 and R3, the variance of the length of the assortment from the nominal length is 11 to $62 \%$ from the number of prepared assortments.

2. In the warm season, with a length measuring roller for the R1 prepared assortments, the deviation from the nominal length $1.5-23.8 \%$ of the number of assortments prepared is observed. With length measurement rollers R2 and R3, the variance of the length of the assortment from the nominal length is $0-22 \%$ of the number of assortments prepared.

3. In cold periods R2 and R3 length measurement rollers gear pairing increases the ability to slip, for that reasonthe accuracy of the length measurement decreases.

4. For richer and longer assortments, there is often a significant difference in the length between nominal sizes (or "longer" ones), with smaller, more rigorous assortments and with negative nominal sizes (or "shorter" ones) with a higher length.

\section{References}

[1] Janak, $\mathrm{K}$ Differences in volume of round Timber caused by different determination methods,Drvna industrija 56 (4), 2005, pp.165-170.

[2] Liepa I., Līpiņš L. Apaļo kokmateriālu uzmērī̌sana. Jelgava: Latgales druka, 2007, 104 lpp. ISBN 5-410-01142-2

[3] Murphy, G.E., Marshall, H.D., Evanson A.W. Production speed effects on logmaking error rates and value recovery for a mechanized processing operation in radiata pine. Southern African Forestry Journal 204,23-35, 2005.

[4] Miklašēvics Z., Neicinieks M. Augšu koku un kokmateriālu kvalitāte. Rīga: Latvijas valsts meži, 2014, 128 lpp.

[5] Janák K., Round Wood Measurement System, In: Advanced Topics in Measurements Edited by Md. Zahurul Haq. Published by InTech Janeza Trdine 9, 51000 Rijeka, Croatia, Vol. 412, 2012, pp. 103-130. 
[6] Dooley T., Layton T., Nieunwenhuis M. The impact of calibration on the accuracy of harvester measurement of total harvest volume and assortiment volume for Sitka spruce clearfells in Ireland. Irish Forestry 96-107, 1995.

[7] Andersso B., Dyson P. Log Measuring Accuracy of Harvesters and Processors. Council of Forest Engineering (COFE) Conference Proceedings: „Appalachian Hardwoods: Managing Change” July 15-18, Vancouver, British Columbia, 2001.

[8] Gellerstedt, S.. Operation of the single-grip harvester: motorsensory cognitive work. Int. J. For. Eng. 13(2): 35-47, 2002.

[9] Strandgard, M., Walsh, D., Maintaining harvester measurement accuracy to maximise value recovery. CRC for Forestry. 1-3. 6/2012, 2012.

[10] Marshall, H. D., Murphy, G. E., Boston, K., Evaluation of the economic impacts of length and diameter measurement error on mechanical harvesters and processors operating in pine stands. Canadian Journal of Forest Research 36(7): 1661-73, 2006.

[11] Strandgard, M., Walsh, D., Maintaining harvester measurement accuracy to maximise value recovery. CRC for Forestry. 1-3. 6/2012, 2012. 